\title{
Simulation of primary particle size distributions in a premixed ethylene stagnation flame
}

\author{
Dingyu Hou ${ }^{\mathrm{a}, \mathrm{b}}$, Casper S. Lindberg ${ }^{\mathrm{c}, \mathrm{d}}$, Mengda Wang,b, Manoel Y. \\ Manuputty ${ }^{\mathrm{c}, \mathrm{d}}$, Xiaoqing You ${ }^{\mathrm{a}, \mathrm{b}, *}$, Markus Kraft ${ }^{\mathrm{c}, \mathrm{d}, \mathrm{e}, *}$ \\ ${ }^{a}$ Center for Combustion Energy, Tsinghua University, Beijing, 100084, China \\ ${ }^{b}$ Key Laboratory for Thermal Science and Power Engineering of the Ministry of \\ Education, Tsinghua University, Beijing, 100084, China \\ ${ }^{c}$ Department of Chemical Engineering and Biotechnology, University of Cambridge, \\ Philippa Fawcett Drive, Cambridge, CB3 0AS, United Kingdom \\ ${ }^{d}$ Cambridge Center for Advanced Research and Education in Singapore (CARES), 1 \\ Create Way, 138602, Singapore \\ ${ }^{e}$ School of Chemical and Biomedical Engineering, Nanyang Technological University, 62 \\ Nanyang Drive, 637459, Singapore
}

\begin{abstract}
Numerical simulation of soot formation in a laminar premixed burner-stabilized ethylene stagnation flame was performed with a detailed population balance model (DPBM) capable of tracking full structural details of aggregates as well as their chemical composition. A thorough parametric sensitivity study was carried out to understand the influence of individual sooting processes on the computed primary particle size distributions (PPSDs). The rate of production of pyrene, coagulation efficiency and surface growth rate were found to have significant effects on the computed PPSDs. Besides, we found that the instantaneous sintering between small primary particles (PP) can affect the computed PPSDs drastically while sintering between large PPs within aggregates only had mild effects. For an ethylene premixed flame with stagnation plate height being $1.2 \mathrm{~cm}$ (Combust. Flame, 198:428-435, 2018), good agreement was obtained between both the computed and measured PPSD and fractal dimension, which supports the current mechanisms contributing to the evolution of PPs, i.e. nucleation, coagulation, surface growth and

\footnotetext{
${ }^{*}$ Corresponding author

Email addresses: xiaoqing.you@mail.tsinghua.edu.cn (Xiaoqing You), mk306@cam.ac.uk (Markus Kraft)
} 
sintering. Moreover, time scale analysis for individual sooting processes was performed to determine the dominant particle processes at different periods of time, which helped explain the evolution of soot morphology.

Keywords: soot morphology, population balance simulation, primary particle size distribution, sintering

\section{Introduction}

Soot, as one of the particulate by-products of the incomplete combustion of hydrocarbon fuels, is a major air pollutant and a potential threat to human health [1, 2]. In contrast, carbon black (CB), a kind of carbonaceous particle sharing similar formation mechanisms with soot, is very versatile in industry, such as reinforcer in automobile tires and pigment in laser printers [1, 3, 4]. Knowledge regarding the mechanisms of soot formation will not only help mitigate pollutant emission during combustion, but also improve the production efficiency of CB in industry. For this purpose, much research has been conducted to explore soot formation mechanisms in the past several decades. Experimentally, a variety of characteristics of soot particles including the volume fraction [5], mobility size [8 10], morphology [11 13], fine structure [14, 15], and molecular composition [16, 17] have been measured using different techniques. Meanwhile, a number of mechanisms for individual sooting processes, for instance the well-known Hydrogen-abstraction- $\mathrm{C}_{2} \mathrm{H}_{2}$ addition (HACA) mechanism for soot surface growth, were proposed [18]. In order to verify whether these hypothesized sub-mechanisms are responsible for soot formation and growth, comparison between the simulated and measured results is required. Therefore, a variety of population balance models for soot have been developed. Performing sensitivity analysis on the basic processes in a soot model and comparing the results with experimental observations give clues to which of the sub-models need to be refined.

In previous modelling work, it is common to compare the computed soot volume fraction [19] or the particle mobility size distributions (PSDs) [2022 with experimental results, while not enough attention has been paid to the simulation of aggregate morphology. One possible reason for the lack of studies on modelling soot aggregate morphology may be the lack of statistical experimental data characterising the morphology, such as the primary particle (PP) number and size distribution [23]. In addition, the limitations of the existing soot models are also responsible for this problem — particle 


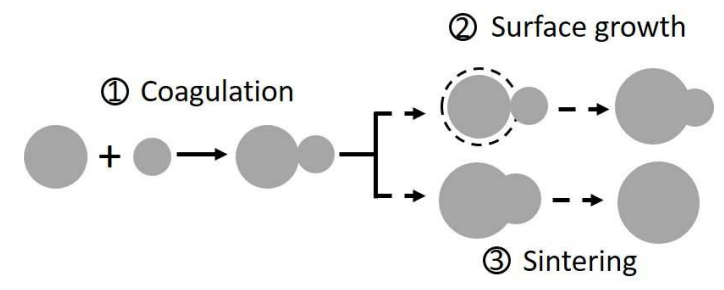

Figure 1: An illustration of coagulation, surface growth and sintering.

models have to be detailed enough to track morphological information, while only a minor number of soot models in literature are capable of capturing full structural information of aggregate particles [24]. However, modelling studies focusing on the morphology of soot aggregates are actually needed, especially in the CB industry, because it is the morphology of CB that determines its end-use and performance, while the current techniques used to control the aggregate morphology are still based on trial and error [25, 26].

Early efforts on modelling aggregate morphology of soot were made by a few researchers. Mitchell and Frenklach [27, 28] simulated the morphological evolution of a single aggregate particle experiencing simultaneous coagulation and surface growth (illustrated by (1) and (2) in Fig. 1) using a dynamic Monte Carlo method and attributed the spheroidal shape of particles to rapid surface growth and intense particle nucleation. (Note that the coagulation process may also named as agglomeration in literature [29], yet for consistency only the term coagulation will be used in this work.) To extend the analysis of the dynamics of a single aggregate to the ensemble-averaged simulations, Balthasar and Frenklach [30] incorporated the results obtained in [27, 28] into the method of moments to calculate soot formation in premixed flames. Further development was made by Morgan et al. [31], who combined the particle model in [27, 28] with an efficient stochastic particle collision algorithm [20, 32, 33] to perform population balance simulations of soot particles in laminar premixed flames. The model of Morgan et al. [31] was capable of tracking full structural details of soot particles undergoing nucleation, coagulation and surface growth. These studies demonstrated that the morphology of aggregate particles was the result of the complex interplay between individual processes - nucleation, surface growth and coagulation [27, 28, 31.

Discrete element modelling (DEM) and moving sectional models are also 
useful tools to investigate the morphological evolution of aggregate particles undergoing several particle processes. For instance, Kelesidis et al. [29] studied the dynamics of carbonaceous aerosols from nascent to mature fully-developed soot structures during simultaneous coagulation and surface growth. Correlations among gyration diameter, mobility diameter, PP diameter and particle effective density accounting for the PP polydispersity and chemical bonding were obtained based on their DEM simulations. Kelesidis and Pratsinis [34] investigated the impact of change of soot morphology on its light absorption properties by coupling DEM with discrete dipole approximation (DDA) during soot surface growth and agglomeration. Kelesidis and Pratsinis [35] studied the evolution of agglomerate soot mass and mobility diameter during both internal and surface oxidation using a moving sectional model.

Besides surface growth and coagulation, which were considered in previous modelling work, the sintering process as illustrated by (3) in Fig. 1, through which particles become more round (reduce surface area) without gaining mass from gas-phase, may also play an important role in the morphological evolution soot particles. Note that sintering may also be named as coalescence in literature [36], while for consistency, only the term sintering will be used in this work. Despite that some researchers speculated sintering was less likely to happen on carbonaceous nanoparticles due to their turbostractic structure [28, 37], Ono et al. [25] provided experimental evidence of sintering of soot particles in their recent work. Moreover, a number of experimental studies showed that nascent soot particles are liquid-like in flames [12, 38 40], which might make them sinter easily after coagulation. Therefore, a model incorporating sintering, coagulation and surface growth can be helpful to reveal the significance of each mechanism on the evolution of particle morphology. Detailed population balance models (DPBMs) for soot, developed by Kraft and co-workers [41 43], provide such an effective tool. In general, a DPBM represents soot particles as aggregates composed of overlapping PPs, where each PP is composed of a number of polycyclic aromatic hydrocarbons (PAHs). Botero et al. 23] employed a DPBM for the first time to investigate the mechanisms that are important for the prediction of the primary particle size distribution (PPSD) in a $\mathrm{C}_{2} \mathrm{H}_{4}$ co-flow laminar diffusion flame. They found that the parameterization of sintering and particle rounding affected the simulated PPSDs significantly. However, the DPBM in [23] did not track the relative position of PPs within aggregates, leaving the aggregate morphology unresolved. A free model parameter, the smooth- 
ing factor $\sigma$, was introduced to account for particle rounding due to mass addition processes, i.e. surface growth and condensation.

Recently, the limitations of the prior DPBM in [23] were overcome by Lindberg et al. [44] and Hou et al. [45] by tracking the coordinates of all PPs, thus the aggregate morphology can be resolved during simulation and the free parameter $\sigma$ in previous DPBMs [23, 42, 43] was eliminated. This allowed more physical description of particle processes such as surface growth and sintering. With this improved DPBM, Hou et al. 45 simulated soot formation in a benchmark premixed ethylene stagnation flame [46] and obtained reasonable agreement between the simulated and measured PSDs. The parametric sensitivity study in [45] showed that the computed mobility diameters of aggregate particles were not very sensitive to the sintering rate, while the size of PPs within aggregate particles can be significantly affected. Since no experimental data on the size of PPs was reported in [46], comparison between the computed and measured PP size could not be conducted.

Recently, Wang et al. [47] reported the measured PPSD of soot particles produced in laminar premixed ethylene flames with conditions similar to the benchmark flame that was simulated in our previous work [45]. It would be of interest to test the performance of this improved DPBM in predicting the morphology of soot particles in premixed flames by comparing with experimental results. Therefore, the purpose of this work is threefold: 1) simulate soot formation in a premixed ethylene stagnation flame employing the improved DPBM [45], which is capable of resolving both morphology and composition of aggregate particles; 2) make quantitative comparison between the computed and TEM-observed PPSD of soot aggregates; 3 ) investigate the influence of key particle processes on the simulated PPSD through parametric sensitivity study, especially the role of sintering in the evolution of soot morphology.

\section{Modelling methodology}

\subsection{Target flame}

In this study, we modelled the burner-stabilized premixed ethylene stagnation flame of Wang et al. [47] (Flame A3 in [47]; stagnation plate height $\left.H_{\mathrm{p}}=1.2 \mathrm{~cm}\right)$. The experimental details are introduced in [47]. Briefly, the unburned gas composition is $16 \% \mathrm{C}_{2} \mathrm{H}_{4}, 24 \% \mathrm{O}_{2}$ and $60 \%$ AR (molar basis); the inlet cold gas velocity is $7 \mathrm{~cm} / \mathrm{s}$ and the temperature is $298 \mathrm{~K}$; the temperature at the stagnation plate is around $465 \mathrm{~K}$. 


\subsection{Flame model}

The axisymmetric stagnation flow in the flame is modelled using a pseudo one-dimensional approximation, which is described in detailed in [10, 43, 48].

\subsection{Gas-phase chemistry model}

The gas-phase chemistry is determined by the ABF mechanism [19], which contains 101 species and 543 reactions, with pyrene (A4) being the largest PAH.

\subsection{Particle model}

Two different particle models - a spherical model and a detailed model were used during different simulation steps serving different purposes, which will be discussed in Section 2.5.

The spherical model, used in the first-step simulation, describes all soot particles as spheres composed of $\mathrm{C}$ atoms only. Three types of particle processes - inception, coagulation and surface reactions are incorporated. Inception is modelled as two A4 molecules sticking after collisions. Coagulation is modelled as the collision and instantaneously merging of two particles. Surface reactions include the reactions of gaseous $\mathrm{C}_{2} \mathrm{H}_{2}, \mathrm{H}, \mathrm{O}_{2}, \mathrm{OH}$ and $\mathrm{A} 4$ with the surface of soot particles. A more detailed description on the spherical model can be found in [19, 49].

The detailed particle model, employed in the post-processing step, represents soot particles as aggregates composed of overlapping spherical PPs, where each PP consists of a number of PAHs. Since a comprehensive description of this detailed particle model has been presented in our previous work [44, 45], only a brief introduction on the most important aspects of the model will be given below. Figure 2 illustrates the type space of the detailed particle model, i.e. the mathematical representation of a particle. An aggregate particle, $P_{q}$, containing $n\left(P_{q}\right)$ overlapping PPs, is represented as

$$
P_{q}=P_{q}\left(p_{1}, \ldots, p_{n\left(P_{q}\right)}, \mathbf{D}\right),
$$

where a $\mathrm{PP} p_{i}$, with $i \in\left\{1, \ldots, n\left(P_{q}\right)\right\}$ is represented as

$$
p_{i}=p_{i}\left(m_{1}, \ldots, m_{n\left(p_{i}\right)}, r_{i}, \mathbf{s}_{i}\right)
$$

where $m_{x}$, with $x \in\left\{1, \ldots, n\left(p_{i}\right)\right\}$, represents the exact structure of a planar PAH; $n\left(p_{i}\right)$ is the total number of PAHs within $p_{i} ; r_{i}$ is the radius of $p_{i}$; $\mathbf{s}_{i}$ represents the position of the center of the PP relative to the center of 


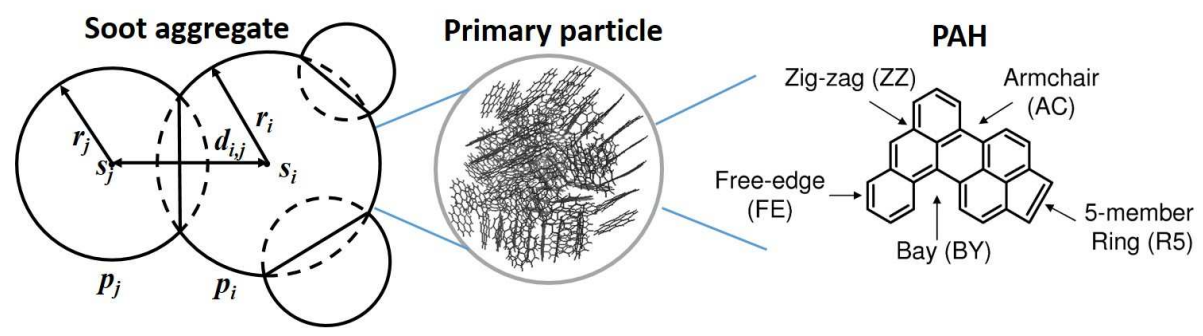

Figure 2: An illustration of the detailed particle model type space showing an aggregate particle (solid outlines) composed of PPs modelled as overlapping spheres (indicated by the dashed lines). PPs are composed of PAHs. The exact structure of PAHs are recorded. Redrawn based on [44, 52, 53.

mass of the aggregate particle; $\mathbf{D}$ is the connectivity matrix used to store the center to center separation $d_{i, j}$ of any two neighboring primaries $p_{i}$ and $p_{j}$. The binary tree data structure is used to store the properties and connections of primaries within an aggregate particle [41, 50]. More detailed discussion regarding this data structure including its merits and constraints can be found in [44]. The volume of a PP is calculated based on the mass of its component PAHs and the mass density of soot, $\rho$, represented as

$$
v\left(p_{i}\right)=\frac{\left(\sum_{x=1}^{n\left(p_{i}\right)} \eta_{\mathrm{C}}\left(m_{x}\right) M_{\mathrm{C}}+\sum_{x=1}^{n\left(p_{i}\right)} \eta_{\mathrm{H}}\left(m_{x}\right) M_{\mathrm{H}}\right) / N_{\mathrm{A}}}{\rho}
$$

where $\eta_{y} \in \mathbb{Z}, \eta_{y}>0$ is the number of chemical units of type $y, y \in\{C, H\}$ [51. $M_{\mathrm{C}}$ and $M_{\mathrm{H}}$ are the molecular weights of $\mathrm{C}$ and $\mathrm{H}$, which are 12.01 and $1 \mathrm{~g} / \mathrm{mol}$, respectively. $N_{\mathrm{A}}$ is the Avogadro constant. The volume of an aggregate particle is defined as the sum of the volumes of all PPs:

$$
V\left(P_{q}\right)=\sum_{n=1}^{n\left(P_{q}\right)} v\left(p_{i}\right)
$$

The diameter of a spherical PP without any overlaps with other PPs is calculated as

$$
d_{s p h}\left(p_{i}\right)=\left(\frac{6 v\left(p_{i}\right)}{\pi}\right)^{1 / 3}
$$

With the detailed particle model type space shown in Fig. 2, $v\left(p_{i}\right)$ can also be given by the volume of a sphere of radius $r_{i}$ minus the volume of the caps created by overlaps with its neighbors as described by the equations 


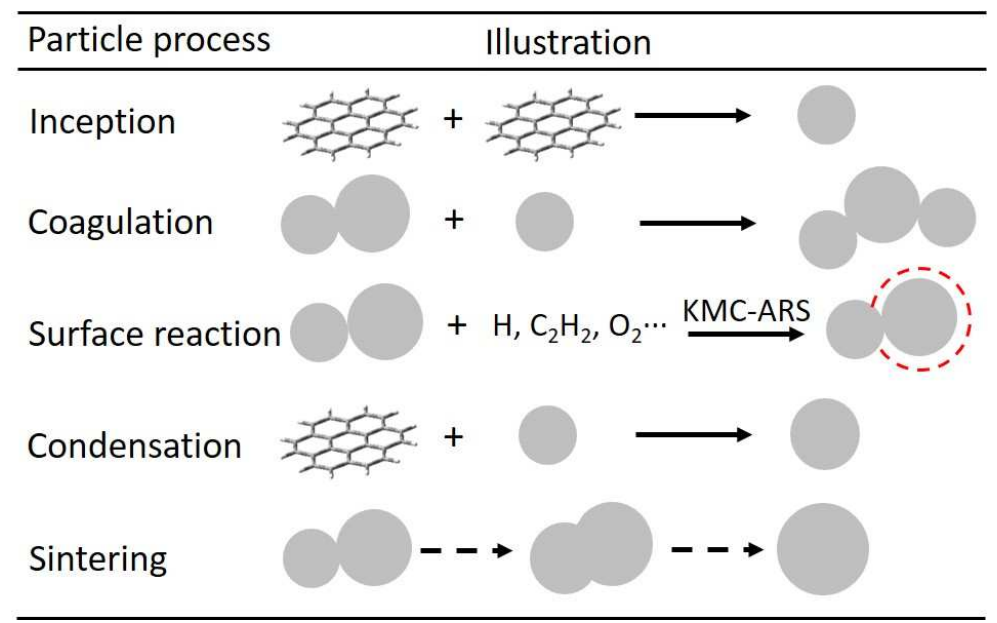

Figure 3: An illustration of particle processes incorporated in the detailed particle model.

in [44, 54]. This approach of describing aggregate particles as overlapping polydispersed PPs is based on the work of Mitchell and Frenklach [27, 28], Morgan et al. [31], Eggersdorfer et al. [54, 55] and Lindberg et al. [44]. The detailed model equations can be found in [44].

The mobility diameter $\left(d_{\mathrm{m}}\right)$ of a spherical particle can be simply calculated by Eq. (5), while $d_{\mathrm{m}}$ of an aggregate is determined by Eq. (6) [29]:

$$
d_{\mathrm{m}}=d_{\mathrm{va}} n_{\mathrm{va}}^{0.45}
$$

where $n_{\mathrm{va}}$ is the equivalent number of PPs, calculated by:

$$
n_{\mathrm{va}}=\frac{m}{m_{\mathrm{va}}}=\frac{m}{\frac{\pi}{6} d_{\mathrm{va}}^{3} \rho},
$$

where $m_{\mathrm{va}}$ is the mass of a PP with diameter $d_{\mathrm{va}}$; $d_{\mathrm{va}}$ is the mean surfaceequivalent diameter [29, 56]:

$$
d_{\mathrm{va}}=\frac{6 V}{S},
$$

where $V$ and $S$ are total aggregate volume and surface area, respectively. The equations used to determine the collision diameter and gyration diameter of both spherical and aggregate particles can be found in our previous work [45].

Five particle processes namely inception, coagulation, surface growth and oxidation, condensation and sintering are incorporated in the detailed particle model and illustrated in Fig. 3. A more detailed description of these 
particle processes can be found in our previous work [44, 45] and references therein.

Inception. Inception is modelled as two gaseous PAH molecules sticking together after collision. Two model parameters - inception mode (combined, minimum, maximum, reduced) and inception threshold are used to determine the sticking probability of two colliding PAHs. For example, the combined mode with inception threshold $=32$ means two PAHs will stick together after collision if the sum of the number of aromatic rings in them exceeds 32 , otherwise inception fails. Detailed discussion regarding the inception process and the influence of inception mode and threshold on the computed soot particle size distributions (PSDs) can be found in our previous work [45].

Coagulation. Coagulation is modelled as two particles (either primary or aggregate particle) sticking in point contact after collision. The rate of coagulation is calculated based on a transition regime coagulation kernel [33] and a coagulation efficiency $(0 \leq \eta \leq 1)$. In one of our recent work [57], a size and temperature dependent coagulation efficiency model of carbonaceous nanoparticles was proposed based on the average particle kinetic energy and the potential well depth (i.e. the minimum interaction energy) between two colliding particles. According to [57], $\eta$ decreases with decreasing particle size and increasing temperature; when particles are larger than $10 \mathrm{~nm}, \eta$ is close to 1 regardless of the temperature. The performance of the $\eta$ was tested in [57] by implementing it to a detailed population balance model and simulating soot PSD and PPSD in benchmark premixed ethylene flames. Compared with $\eta=1$ better agreement between the computed PSD and PPSD and the measured ones was achieved with the $\eta$ proposed in [57]. The orientations of colliding particles and point of contact are determined by ballistic clustercluster aggregation (BCCA) with a random impact parameter [58]. More detailed description can be found in [44].

Surface reaction. Surface growth and oxidation of a soot particle are modelled as the reactions of the PAHs inside the particle with gas-phase species, such as $\mathrm{H}$ and $\mathrm{C}_{2} \mathrm{H}_{2}$. The evolution of an individual $\mathrm{PAH}$ is described by the kinetic Monte-Carlo Aromatic Site (KMC-ARS) model [52, 59], where the reactions of PAH molecules are simplified to around 20 jump processes using the steady-state assumption. Two parameters - the critical number of PAHs inside a PP $n_{\text {crit }}$ and the growth factor $g$ are introduced to differentiate $\mathrm{PAH}$ growth in a large PP from growth in a small one [41 43]. If the number of PAHs in a PP exceeds $n_{\text {crit }}$, a growth factor $g \in[0,1]$ will be applied to the growth rate as a multiplier for all PAHs within that PP. 
Condensation. Condensation is modelled as a gaseous PAH molecule sticking to a particle (either primary or aggregate particle) following a collision between them. A free model parameter - the condensation threshold is introduced to describe the sticking efficiency between a PAH and a particle. The sticking efficiency is 1 if the number of aromatic rings of the colliding PAH exceeds the condensation threshold, otherwise it is 0 [43, 45].

Sintering. Sintering refers to the process through which an aggregate particle becomes more round without gaining mass from gas-phase species. In the model, sintering is performed individually on each pair of neighboring primaries, $p_{i}$ and $p_{j}$ in an aggregate. During sintering, the centers of $p_{i}$ and $p_{j}$ approach and the diameters of $p_{i}$ and $p_{j}$ increase. Detailed mathematical description of sintering based on the aforementioned particle type space can be found in [44, 54]. The sintering rate $R_{\text {sint }}$ is calculated by Eq. (9) [60]

$$
R_{\mathrm{sint}}=1 / \tau_{\mathrm{s}}=1 /\left\{A_{\mathrm{s}} d_{i, j} \exp \left[\frac{E_{\mathrm{s}}}{T}\left(1-\frac{d_{\text {crit }}}{d_{i, j}}\right)\right]\right\},
$$

where $\tau_{\mathrm{s}}$ is the characteristic sintering time; $A_{\mathrm{s}}(\mathrm{s} / \mathrm{m})$ is the pre-exponential factor; $d_{i, j}(\mathrm{~nm})$ is the minimum diameter of two neighboring PPs $(i$ and $j$ are indices of the two neighboring $\mathrm{PPs}) ; E_{\mathrm{s}}(\mathrm{K})$ is the activation energy and $d_{\text {crit }}(\mathrm{nm})$ is the critical PP diameter below which PPs are assumed to be liquid-like and will sinter instantaneously [60]. Eq. (99) was first proposed by Tsantilis et al. [60] to model the sintering process of silica particles. Chen et al. [42] incorporated this sintering sub-model to the DPBM of soot, with parameters $A, E_{\mathrm{s}}$ and $d_{\text {crit }}$ (listed in Table 1) obtained by fitting the computed PSDs of soot to the measured results in premixed ethylene flames.

\subsection{Numerical method}

The numerical method consists of two steps. The purpose of the first-step simulation is to calculate the flame profile by coupling a gas-phase reaction model, a flow model and a spherical particle model. In this way, the effect of soot particle processes, i.e. inception and surface reactions on key gasphase species can be approximately accounted for. Method of moments with interpolative closure (MoMIC) is employed to close the moment transport

equations [61]. The inetics $^{\circledR}$ software package [62] is used to perform the first-step simulation.

In the second simulation step, the calculated gas-phase species profile is post-processed with a detailed particle model to resolve the morphology 
of soot particles. The second step is one-way coupling as the effect of the particles on the gas-phase has already been accounted for in the gas-phase profile imposed in the second step. The particle population balance is solved by a stochastic method, with various enhancements to improve the efficiency [33, 63, 64]. This two-step modelling methodology is well established and has been applied in a number of previous works [23, 42, 43, 65]. Recently, Lindberg et al. 66] extended this methodology for stagnation flames [45]. Detailed discussion regarding this methodology can be found in [66].

\section{Results and discussion}

Our previous work [45] focused on simulating the mobility diameter $d_{\mathrm{m}}$ of soot particles in premixed ethylene stagnation flames. However, two aggregate particles with different morphology, for instance, one aggregate particle composed of a large number of small PPs and the other composed of a small number of large PPs, can have similar $d_{\mathrm{m}}$. Therefore, besides the size of aggregate particles, the size of PPs will become the main issue of this work.

\subsection{Parametric sensitivity study}

A thorough parametric sensitivity study was carried out to understand the influence of key particle processes on the computed PPSDs. The initial values of key model parameters are based on our previous work [45] as listed in Table 1. When examining the influence of a certain parameter on the computed PPSD, the remaining parameters were assigned their initial values. The influence of five model parameters including the rate of production of A4 $\dot{\omega}_{A 4}$, coagulation efficiency $\eta$, surface growth factor $g$, pre-exponential factor $A_{\mathrm{s}}$ and critical diameter of PP $d_{\text {crit }}$ in the sintering sub-model on the computed PPSD will be investigated. Among these parameters, $\dot{\omega}_{A 4}$ relates to the nucleation rate; $\eta$ affects the coagulation rate; $g$ controls the surface growth rate of large PPs; $A_{\mathrm{s}}$ and $d_{\text {crit }}$ determine the sintering rate.

Figure 4(a) shows the effect of $\dot{\omega}_{A 4}$ on the computed PPSDs. Although $\dot{\omega}_{A 4}$ is not the same as nucleation rate since one A4 molecule is not the equiv-

alent of one nucleated soot particle, A4 molecules are the starting point of the post-processing step. They will grow up into larger PAHs based on the KMC-ARS model [52, 59] and then two PAHs will stick after collision to form a nucleus if their total number of aromatic rings exceeds the inception threshold. To investigate the influence of $\dot{\omega}_{A 4}$ on the simulated PPSDs, two multipliers - 0.5 and 2.0 were applied to the original $\dot{\omega}_{A 4}$ profile and served 
Table 1: Key model parameters in the detailed soot model.

\begin{tabular}{lll}
\hline Parameter & Value & Ref. \\
\hline $\begin{array}{l}\text { (1) Material property } \\
\text { Soot density } \rho\left(\mathrm{g} / \mathrm{cm}^{3}\right)\end{array}$ & 1.0 & [45, 47, 67] \\
\hline $\begin{array}{l}\text { (2) Nucleation } \\
\dot{\omega}_{\mathrm{A} 4}\left(\mathrm{~mol} /\left(\mathrm{cm}^{3} \mathrm{~s}\right)\right)\end{array}$ & Gas-phase input & \\
$\begin{array}{l}\text { Inception mode } \\
\text { Inception threshold }{ }^{\mathrm{a}}\end{array}$ & Combined & {$[45]$} \\
\hline $\begin{array}{l}\text { (3) Condensation } \\
\text { Condensation threshold }\end{array}$ & 32 & {$[45]$} \\
\hline $\begin{array}{l}\text { (4) Surface growth } \\
\text { Critical num. of PAH } n_{\text {crit }}\end{array}$ & $1,50^{\mathrm{b}}$ & {$[45]$} \\
Growth factor $g$ & $1,0.0263^{\mathrm{b}}$ & {$[42,45]$} \\
\hline
\end{tabular}

(5) Coagulation

Efficiency $\eta$

1, Size \& $T$ dependent ${ }^{b}$

57

(6) Sintering

$A_{\mathrm{s}}(\mathrm{s} / \mathrm{m})$

$E_{\mathrm{s}}(\mathrm{K})$

$d_{\text {crit }}(\mathrm{nm})$

$1.10 \times 10^{-14}$

$9.61 \times 10^{4}$

$1.58,3.0^{\mathrm{b}}$

[42, 43, 45]

a The unit is number of aromatic rings.

b Values applied when performing comparison between the computed and measured morphology of soot particles.

as the input to the post-processing step. As shown in Fig. 4(a), the computed PP diameter is larger when a larger $\dot{\omega}_{A 4}$ profile is employed. This is because larger $\dot{\omega}_{A 4}$ results in more PAHs and thus more small particles, which promotes coagulation and condensation. If one of the coagulating particles is smaller than $d_{\text {crit }}$, the two PPs will merge into one larger PP immediately after coagulation because the sintering rate dictated by Eq. (9) is much faster than the coagulation rate. The geometric standard deviations $\left(\sigma_{\mathrm{g}}\right)$ of the computed PPSDs which can reflect the degree of dispersion of the PP size are also given in Fig. $4(\mathrm{a})$, It suggests that increase in $\dot{\omega}_{A 4}$ will decrease the polydispersity of PP size slightly, yet the effect is almost negligible. This is in accordance with the DEM simulation performed by Kelesidis et al. [29], who 


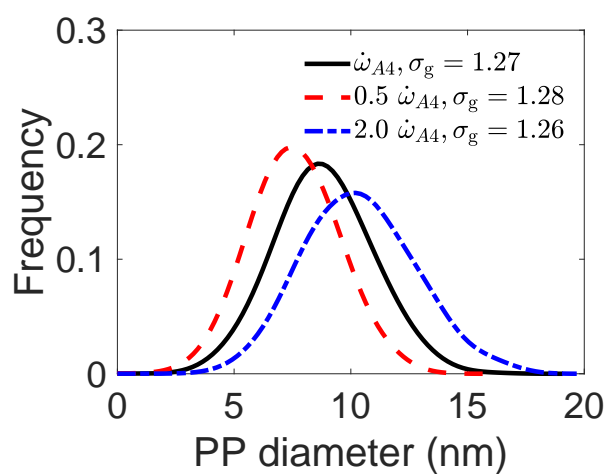

(a)

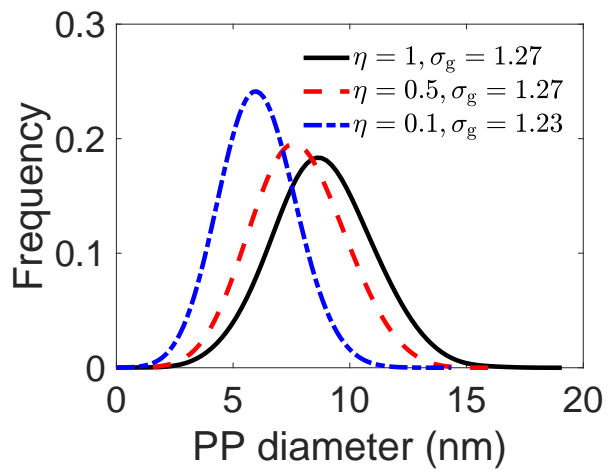

(c)

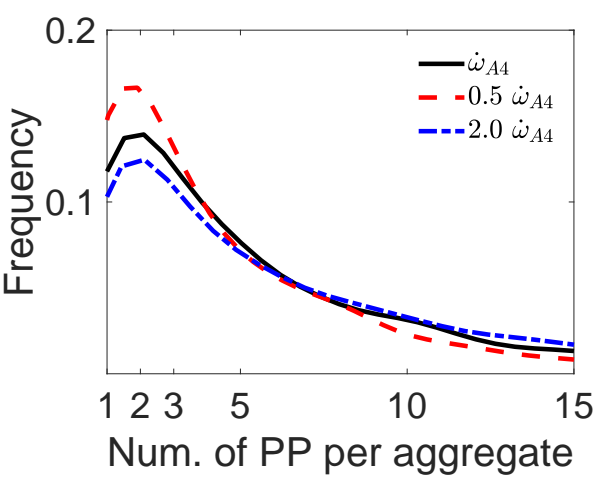

(b)

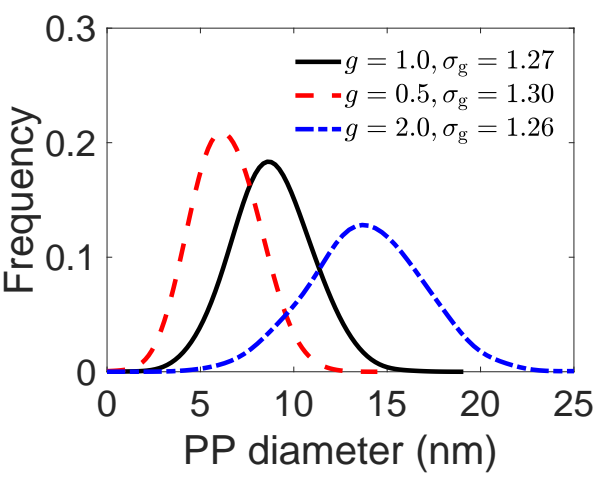

(d)

Figure 4: The computed PPSDs (a) and the distribution of number of PPs per aggregate (b) with different rate of production of A4 $\left(\dot{\omega}_{A 4}\right)$; The computed PPSDs with (c)] different coagulation efficiency and (d) different surface growth rate. The geometric standard deviations $\left(\sigma_{\mathrm{g}}\right)$ of the PP diameter are also shown.

reported the number of nucleated soot particles within a factor of 4 would not affect the simulation results significantly. In addition to the computed PPSDs, the effect of $\dot{\omega}_{A 4}$ on the computed distribution of number of PP per aggregate was also investigated. As shown in Fig. 4(b), the computed aggregate particles tend to contain more PPs if a larger $\dot{\omega}_{A 4}$ is used. This is because larger $\dot{\omega}_{A 4}$ increases the number of particles by increasing number of freshly nucleated particles, thus promoting coagulation and resulting in aggregate particles containing more PPs.

Figure 4(c) shows the influence of coagulation efficiency $\eta$ on the computed PPSDs. $\eta=1$ leads to larger PPs than $\eta=0.5$ or 0.1. Although 
coagulation does not affect PP size directly, the coagulation between particles with diameter smaller than $d_{\text {crit }}$ will lead to a larger PP because the sintering rate determined by Eq. (9) is infinitely fast under such condition. Therefore, PPs tend to be larger with a higher $\eta$. $\sigma_{\mathrm{g}}$ shown in Fig. 4(c) suggests that PP size spreads out more with $\eta=1$ and 0.5 than that with a much lower $\eta, 0.1$. This can be explained by imagining an extreme case with $\eta=0$, where PPs grow in size solely by gaining mass from gas-phase and hence the PP size has a narrow distribution.

Surface growth of soot particles is modelled as the growth of their constituent PAHs, which is described by the KMC-ARS model [52, 59]. In order to study the effect of surface growth rate on the computed PPSDs, different multipliers i.e. growth factor $g$ were applied. Note that although the original purpose of model parameters $g$ and $n_{\text {crit }}$ were to consider the steric effects on particle surface growth, i.e. to differentiate the growth rate of a gas-phase $\mathrm{PAH}$ and that of a PAH inside a large PP composed of many PAHs, here we only focused on the effect of surface growth rate while the steric effects are neglected, i.e. $n_{\text {crit }}=1$ no matter what value of $g$ was. As shown in Fig. 4(d), surface growth rate affects the shape of the computed PPSDs significantly. A faster surface growth rate results in larger PPs yet with a smaller $\sigma_{\mathrm{g}}$. This is because surface growth can make the aggregate particle more round by 'burying' the neck between its constituent PPs, which is consistent with the simulation results reported by Mitchell and Frenklach [27, 28] and Kelesidis et al. [26].

As introduced in Section 2.4, sintering will result in more round particles without gaining mass from gas-phase. However, large uncertainties of the parameters of the current sintering sub-model for soot could exist, although reasonable agreement between the computed and measured PSDs was achieved with the optimized $A_{\mathrm{s}}, E_{\mathrm{s}}$ and $d_{\text {crit }}$ shown in Table 1 [42]. This is because this set of parameters was obtained by fitting the computed PSDs to the measured ones in a series of ethylene premixed flames [42], yet the computed PSD was not sensitive to $d_{\text {crit }}$, as demonstrated in our recent work 45]. Figure 5(a) shows the effect of sintering rate on the computed PPSDs by changing $d_{\text {crit }}$ in Eq. (9). The initial value of $d_{\text {crit }}=1.58 \mathrm{~nm}$ is reported by Chen et al. [42], indicating that when PP diameter is smaller than $1.58 \mathrm{~nm}$, it is liquid-like and will merge with its neighbor immediately to form a single bigger PP. Larger $d_{\text {crit }}$ will lead to more instantaneously merging processes between neighboring PPs, thus PPs are larger with $d_{\text {crit }}=3.0 \mathrm{~nm}$ and even larger with $d_{\text {crit }}=5.0 \mathrm{~nm}$. The case with $d_{\text {crit }}=0 \mathrm{~nm}$ was also examined, in 


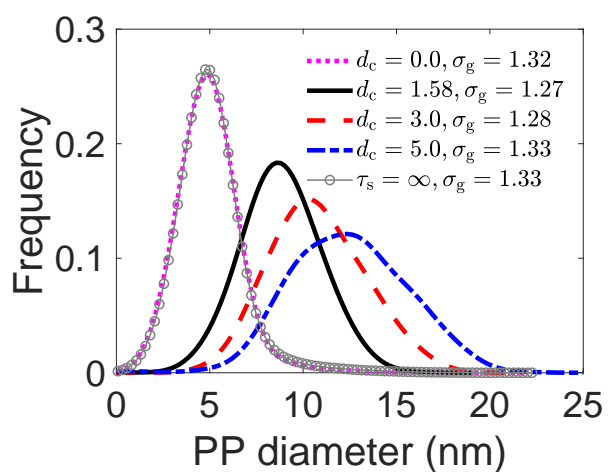

(a)

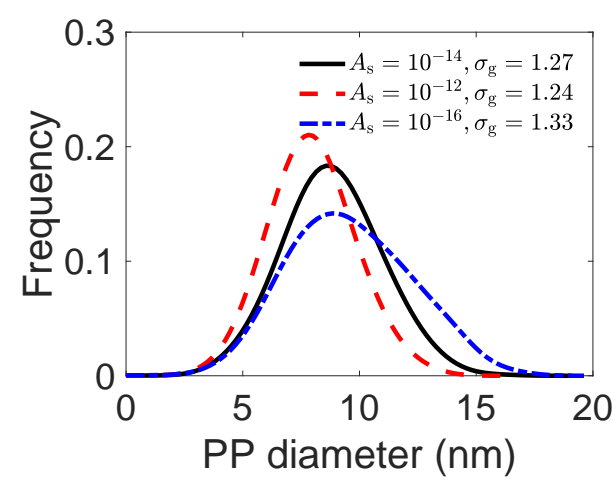

(b)

Figure 5: The computed PPSDs with different sintering rates. The sintering rate is changed by changing (a) $d_{\text {crit }}(\mathrm{nm})$ and (b) $A_{\mathrm{s}}\left(\mathrm{s} \mathrm{m}^{-1}\right)$ in Eq. (9), respectively. $d_{\mathrm{c}}$ is short for $d_{\text {crit }} . \sigma_{\mathrm{g}}$ is the geometric standard deviation of the computed PP size.

which there was no fast merging between small PPs. It is noteworthy that $d_{\text {crit }}=0 \mathrm{~nm}$ does not mean the sintering rate is zero, instead the characteristic sintering time becomes

$$
\tau_{\mathrm{s}}=A_{\mathrm{s}} d_{i, j} \exp \left[\frac{E_{\mathrm{s}}}{T}\right] .
$$

Although two colliding nascent soot particles cannot fuse into one larger particle immediately, they will still sinter at the rate dictated by Eq. (10) and eventually merge into a single spherical particle if the residence time is long enough. However, we found that the computed PPSD with $d_{\text {crit }}=0 \mathrm{~nm}$ (magenta dotted line) almost coincides with that when the sintering submodel is turned off, i.e. $\tau_{\mathrm{s}}=\infty$ (solid gray line with open circles). This indicates the instantaneous sintering of small PPs, which is governed by $d_{\text {crit }}$ in the sintering sub-model, can significantly affect the computed morphology of soot particles, while the sintering of large PPs within soot particles is rather slow and can hardly affect the computed aggregate morphology. In addition, $\sigma_{\mathrm{g}}$ in Fig. 5(a) indicates that $d_{\text {crit }}=1.58$ and $3.0 \mathrm{~nm}$ lead to lower polydispersity of the PP size compared with $d_{\text {crit }}=0$ or $5.0 \mathrm{~nm}$, suggesting the instantaneous sintering between small PPs with diameter smaller than $d_{\text {crit }}$ can decrease the PP polydispersity only when $d_{\text {crit }}$ is in a certain range.

Figure 5(b) shows the influence of sintering rate on the computed PPSDs by changing the prefactor $A_{\mathrm{s}}$. The initial value of $A_{\mathrm{s}}=10^{-14} \mathrm{~s} / \mathrm{m}$ is taken 
from Chen et al. [42. Two more cases are studied with $A_{\mathrm{s}}$ increased or decreased by two orders of magnitude. Since $d_{\text {crit }}=1.58 \mathrm{~nm}$ remains unchanged when changing $A_{\mathrm{s}}$, the instantaneous sintering process between small PPs dictated by $d_{\text {crit }}$ is not affected. Therefore, changing $A_{\mathrm{s}}$ mainly affects the sintering between large PPs within soot aggregates. As demonstrated by Fig. 5(b), PPs are larger when $A_{\mathrm{s}}=10^{-16} \mathrm{~s} / \mathrm{m}$ and smaller when $A_{\mathrm{s}}=10^{-12} \mathrm{~s} / \mathrm{m}$, because a smaller $A_{\mathrm{s}}$ leads to faster sintering rate and thus larger PPs. Besides, with a given $d_{\text {crit }}(=1.58 \mathrm{~nm}), \sigma_{\mathrm{g}}$ is larger with a smaller $A_{\mathrm{s}}$, indicating the PP size spreads out more with faster sintering rate. However, compared with $d_{\text {crit }}$, the effect of $A_{\mathrm{s}}$ on the computed PPSDs is much milder as in Fig. 5(b) $A_{\mathrm{s}}$ was changed by two orders of magnitude while in Fig. 5(a), $d_{\text {crit }}$ was changed within a factor of 5 . Figure 5(a) and (b) together suggest that the immediate sintering of small PPs, which is determined by $d_{\text {crit }}$, plays a critical role in the computed aggregate morphology. However, as mentioned earlier, large uncertainties could exist in $d_{\text {crit }}$. Given its significant influence on the predicted size of PPs, further study regarding the fast sintering between small PPs, especially that from a fundamental point of view, is imperative to provide more instructive guidance on modelling the morphology of soot particles.

\subsection{Comparison with experimental results}

In succession to our previous work, where the ability of the DPBM to predict the PSD of soot formed in premixed ethylene flames was investigated [45], the performance of the model in predicting the morphology of soot aggregates will be tested in this work by comparing the computed PPSD of soot particles with the experimental PPSD based on TEM images of soot aggregates [47.

Numerical simulation of soot formation in Flame A3 in [47] with $H_{\mathrm{p}}=$ $1.2 \mathrm{~cm}$ was carried out with the values of key model parameters listed in Table 1. Before comparing the computed and observed PPSD, the calculated and measured volume fraction $\left(F_{\mathrm{v}}\right)$ and PSD were compared first. The deviation of the computed $F_{\mathrm{v}}\left(7.1 \times 10^{-9}\right)$ from the measured value $\left(2.5 \times 10^{-8}\right)$ is around a factor of 3.5. Such agreement between the calculated and observed $F_{\mathrm{v}}$ is acceptable since the uncertainty of experimental data can also reach a factor of 3.5, as demonstrated by Fig.S1 in the supporting information (SI), where the uncertainties of measured $F_{\mathrm{v}}$ as a function of $H_{\mathrm{p}}$ are shown with experimental data extracted from Camacho et al. [46]. Besides $F_{\mathrm{v}}$, reasonable agreement between the computed and measured PSD was also obtained for 


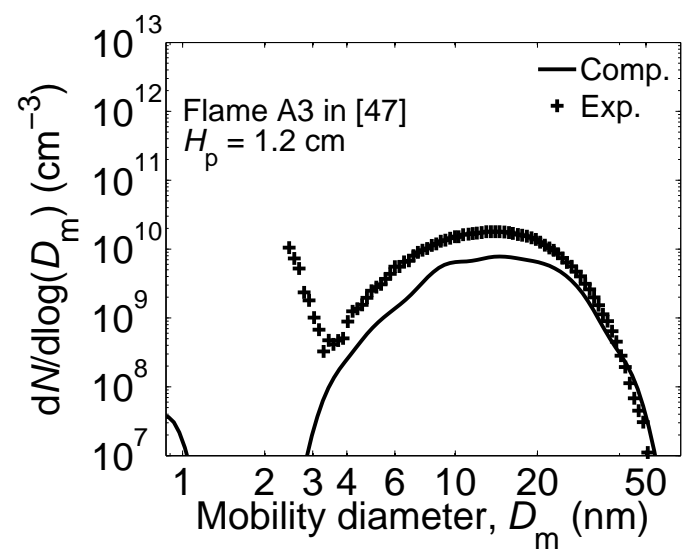

Figure 6: Comparison between the computed and measured PSD. The measured PSD is taken from [47.

particles with $d_{\mathrm{m}}$ larger than $3 \mathrm{~nm}$ as shown in Fig. 6. As the calculated $F_{\mathrm{v}}$ and PSD are consistent with experimental measurements, further comparison regarding the calculated and observed morphology of soot aggregates was made. As illustrated by Fig. 7 , the computed TEM-style images of soot particles with $d_{\mathrm{m}} \approx 50 \mathrm{~nm}$ appear quite similar with the experimentally observed TEM images reported by Wang et al. [47]. More quantitative comparison was made by examining the computed PPSD in this work and the measured PPSD reported in [47], which was obtained by measuring the size of PPs in the observed TEM images for particles with $d_{\mathrm{m}} \approx 50 \mathrm{~nm}$ using the software Image-Pro Plus [68]. For comparison, we have analyzed the size of all PPs within aggregates of $d_{\mathrm{m}}$ in the range of $40-50 \mathrm{~nm}$ based on our computational results and plotted the PPSD in Fig. 7. Normal distributions fitted to the computed and measured PPSDs with corresponding fitted parameters, the median diameter $\mu$ and standard deviation $\sigma$, are shown in Fig. 7. Figure 7 demonstrates good agreement between the computed and the measured PPSD - not only are both of them unimodal, but they also have similar $\mu$, $\sigma$ and $\sigma_{\mathrm{g}}$. In addition to PPSD, we also calculated the fractal dimension $\left(D_{\mathrm{f}}\right)$ of the simulated soot aggregates. Calculation details including a scatter diagram (Fig. S2) of the equivalent number of PPs within an aggregate, $n_{\text {va }}$, versus the ratio of the gyration diameter to the mean surface-equivalent diameter, $d_{\mathrm{g}} / d_{\mathrm{va}}$, and corresponding equations in determining $D_{\mathrm{f}}$ are provided in SI. $D_{\mathrm{f}}=1.37$ was obtained based on our simulation, which agrees well with the measured results $\left(1.33 \leq D_{\mathrm{f}} \leq 1.64\right)[13$ for soot aggregates in 


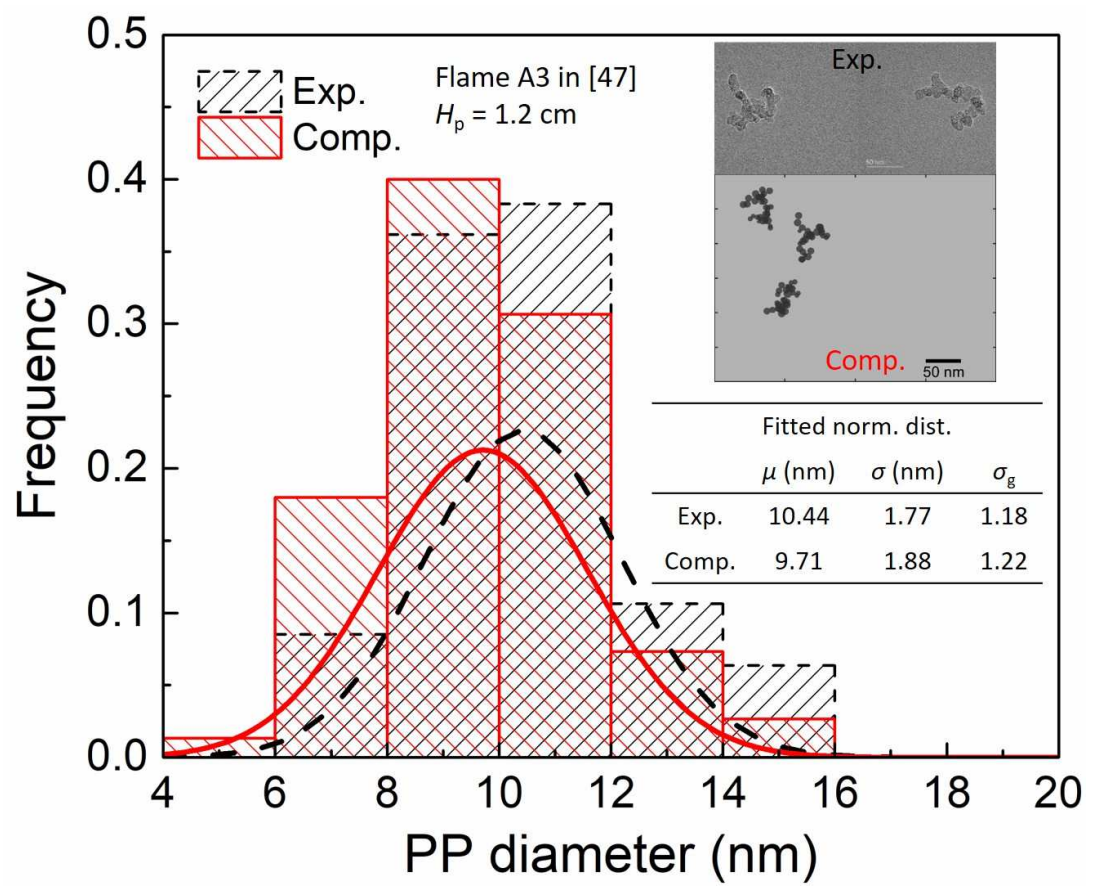

Figure 7: Comparison between the computed and experimental measured PPSD. Lines are the fitted normal distributions. Corresponding fitted parameters, the median diameter $\mu$ and standard deviation $\sigma$ are listed. $\sigma_{\mathrm{g}}$ is the geometric standard deviation. A representative experimental TEM image and a computed TEM-style image of soot particles with $d_{\mathrm{m}} \approx 50 \mathrm{~nm}$ are embedded. The measured PPSD and experimental TEM image are taken from [47.

premixed ethylene flames. The agreement in both computed and measured PPSD and $D_{\mathrm{f}}$ for soot in a premixed ethylene flame with $H_{\mathrm{p}}=1.2 \mathrm{~cm} \mathrm{sup-}$ ports the current hypothesized mechanisms contributing to the evolution of PPs - nucleation, coagulation, surface growth and sintering.

It is also pertinent to mention a recent study of Botero et al. [23], who investigated the evolution of PPs along the centreline of a co-flow laminar diffusion flame both experimentally and numerically. According to their experimental results [23], PPSDs at all heights-above-burner (HAB) were unimodal with a narrow width. However, the computed PPSDs were multi-modal at all HABs. The disagreement between the computed and measured PPSDs might due to the limitations of the DPBM employed in [23], where the aggregate morphology was undetermined. In contrast, current DPBM overcomes the limitation by tracking PP coordinates. The improvement of the DPBM 
may be part of the reason for the good agreement between the computed and measured PPSD in the current work. However, to examine whether the computed multi-modal PPSDs in [23] are due to the imperfection of the previous DPBM or some other factors, soot formation in the laminar diffusion ethylene flame in [23] needs to be investigated with the improved DPBM, which will be one of our future study.

Despite the encouraging agreement, it is worth emphasizing that several model parameters may have large uncertainties due to the lack of understanding of individual sooting processes at current stage. For example, $d_{\text {crit }}$, below which PPs will sinter instantaneously, is assigned $3 \mathrm{~nm}$ in current work. Although excellent agreement between the computed and measured PPSD was obtained, more fundamental investigation such as molecular dynamics studies on the sintering of soot particles is desired to provide evidence for the evaluation of $d_{\text {crit }}$.

Wang et al. [47] only examined the PPSD of soot particles with $d_{\mathrm{m}} \approx$ $50 \mathrm{~nm}$, while PPSDs of soot particles of other $d_{\mathrm{m}}$ were not investigated experimentally. Hence, we studied whether the PPSD was sensitive to the size of aggregates from the modelling point of view. Normal distributions fitted to the computed PPSDs for soot particles with different $d_{\mathrm{m}}, 20,30$ and $40 \mathrm{~nm}$ are plotted in Fig. 8. Corresponding fitted parameters, $\sigma$ and $\mu$ are also listed. The computed PPSDs in Fig. 8 almost coincide with each other regardless of $d_{\mathrm{m}}$, demonstrating that PPSDs are insensitive to the size of aggregates. This suggests that the size of PP may become unchanged after a certain period of time and particles grow in size mainly through coagulation. An in-depth discussion of this point will be given in subsequent sections.

\subsection{Time scale analysis for individual processes}

Soot formation is rather complicated as multiple particle processes may be happening at the same time. To determine the dominant particle processes at different stages of particle evolution, we examined the rate of individual sooting processes and plotted the results in Fig. 9. The rate of production of A4 $\left(\dot{\omega}_{A 4}\right)$, represented by the red solid line, is calculated from the first-step simulation reflecting the inception intensity. The collision rate represented by the blue dashed line is the sum of the majorant kernels of all collision processes, namely inception (collisions between PAH molecules), condensation (collisions between PAH molecules and particles) and coagulation (collisions between particles). The majorant kernel is close to but larger than the real coagulation kernel, which is an algorithm used to speed up the stochastic 


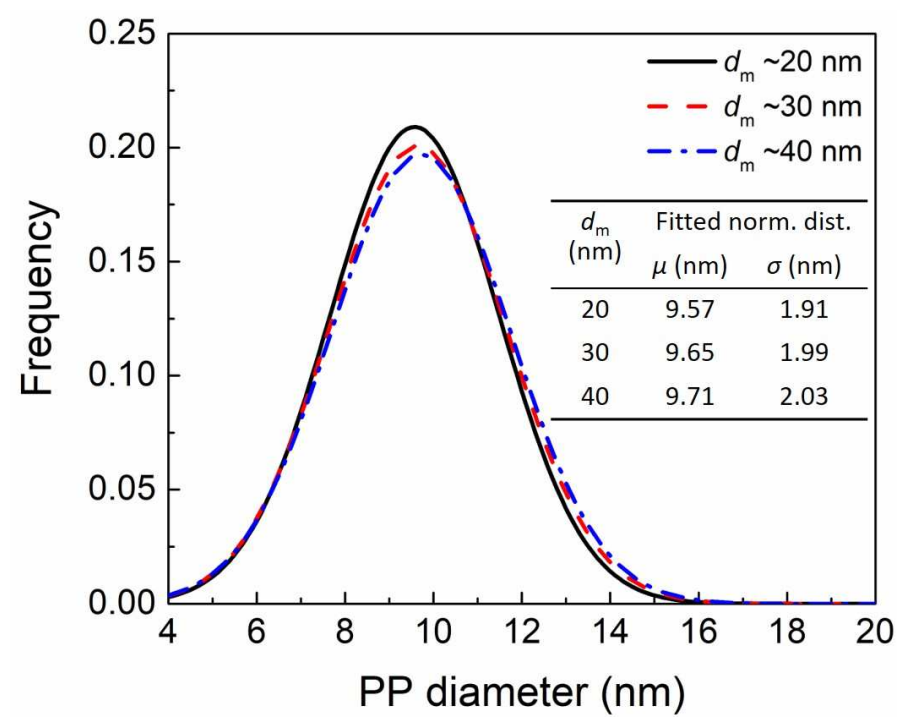

Figure 8: The computed PPSDs (fitted normal distributions) of soot particles with different $d_{\mathrm{m}}$. Corresponding parameters, the median diameter $\mu$ and standard deviation $\sigma$ are listed.

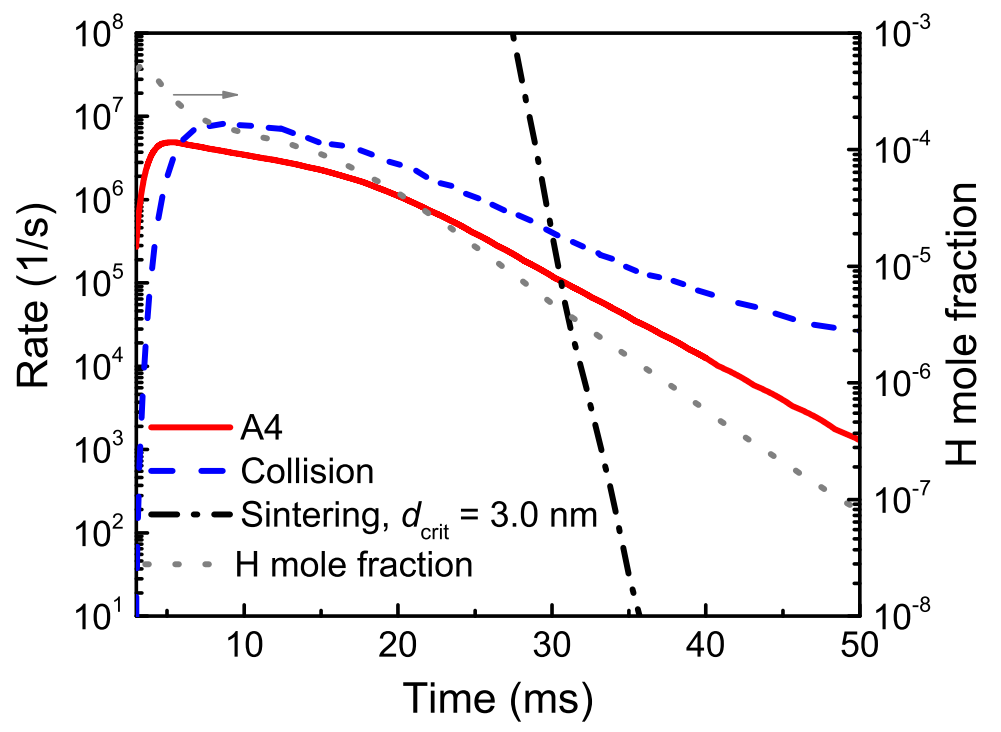

Figure 9: The rate of production of A4, collision rate and sintering rate (left Y-axis) and mole fraction of $\mathrm{H}$ (right $\mathrm{Y}$-axis) against time.

simulations by reducing the complexity associated with solving the coagula- 
tion process [49. The sintering rate, represented by the dash-dotted line, is calculated based on Eq. (9), where $d_{i, j}$ is estimated by the average diameter of all PPs. The curve for sintering rate is quite steep - before $30 \mathrm{~ms}$, it is several orders of magnitudes higher than other processes, while after $30 \mathrm{~ms}$, it nearly stops. This is because the sintering rate is very sensitive to the PP diameter, as $d_{\text {crit }} / d_{i, j}$ is in the exponential term of Eq. (9). The mole fraction of $\mathrm{H}$ atoms is also plotted in Fig. 9 to indicate the rate of surface growth. According to the $\mathrm{H}$-abstraction- $\mathrm{C}_{2} \mathrm{H}_{2}$-addition (HACA) mechanism [18] for soot surface growth, $\mathrm{H}$ atoms are required to provide growth sites for $\mathrm{C}_{2} \mathrm{H}_{2}$ molecules through $\mathrm{H}$ abstraction reactions. Therefore, surface growth rate will be extremely low when the mole fraction of $\mathrm{H}$ drops to $10^{-6}$. Hence, after $30 \mathrm{~ms}$, coagulation becomes the only dominant process. This is in line with our inference from Fig. 8 that particles grow in size mainly through coagulation after a certain period of time. By contrast, before $30 \mathrm{~ms}$, the sintering rate can be several orders of magnitude larger than the rate of coagulation, hence aggregate structure can hardly appear at an early time stage.

With the knowledge gained from the time scale analysis of individual particle processes, the evolution of average PP size and number of PPs per aggregate was investigated. As illustrated in Fig. 10, based on the slope of the average $d_{\mathrm{PP}}$ against time, the growth of $\mathrm{PP}$ can be divided into three stages shown by the vertical dashed lines. The first stage spans from the beginning to $30 \mathrm{~ms}$, where the growth of PPs is due to fast surface growth and instantaneous sintering between small PPs. Soot particles appear to be spherical at this stage, as the average number of PP per aggregate $\sim 1$, consistent with the time scale analysis for sintering process in Fig. 9. The second stage spans from 30 to $50 \mathrm{~ms}$, where the growth rate of PPs gradually slows down, as the slope of the average $d_{\mathrm{PP}}$ with time is decreasing. This slow growth rate is also consistent with Fig. 9, which demonstrates that both sintering and surface growth rates are rather slow during this time period. The last stage spans from $50 \mathrm{~ms}$ to the end of simulation, where the average $d_{\mathrm{PP}}$ almost remains unchanged with time, indicating both surface growth and sintering nearly cease. At this stage, coagulation becomes the leading process. The average number of PPs per aggregate increases linearly with time. This can well explain the simulation results shown in Fig. 8, where the computed PPSDs for aggregate particles with different $d_{\mathrm{m}}$ are quite similar. According to Fig. 10, $n_{\mathrm{PP}}$ per aggregate reaches 2 at $\sim 50 \mathrm{~ms}$, indicating most aggregate particles with $d_{\mathrm{m}} \geq 20 \mathrm{~nm}$ are formed after $50 \mathrm{~ms}$, i.e. particles grow up from $d_{\mathrm{m}}=20 \mathrm{~nm}$ to $d_{\mathrm{m}}=50 \mathrm{~nm}$ mainly by coagulation, which 


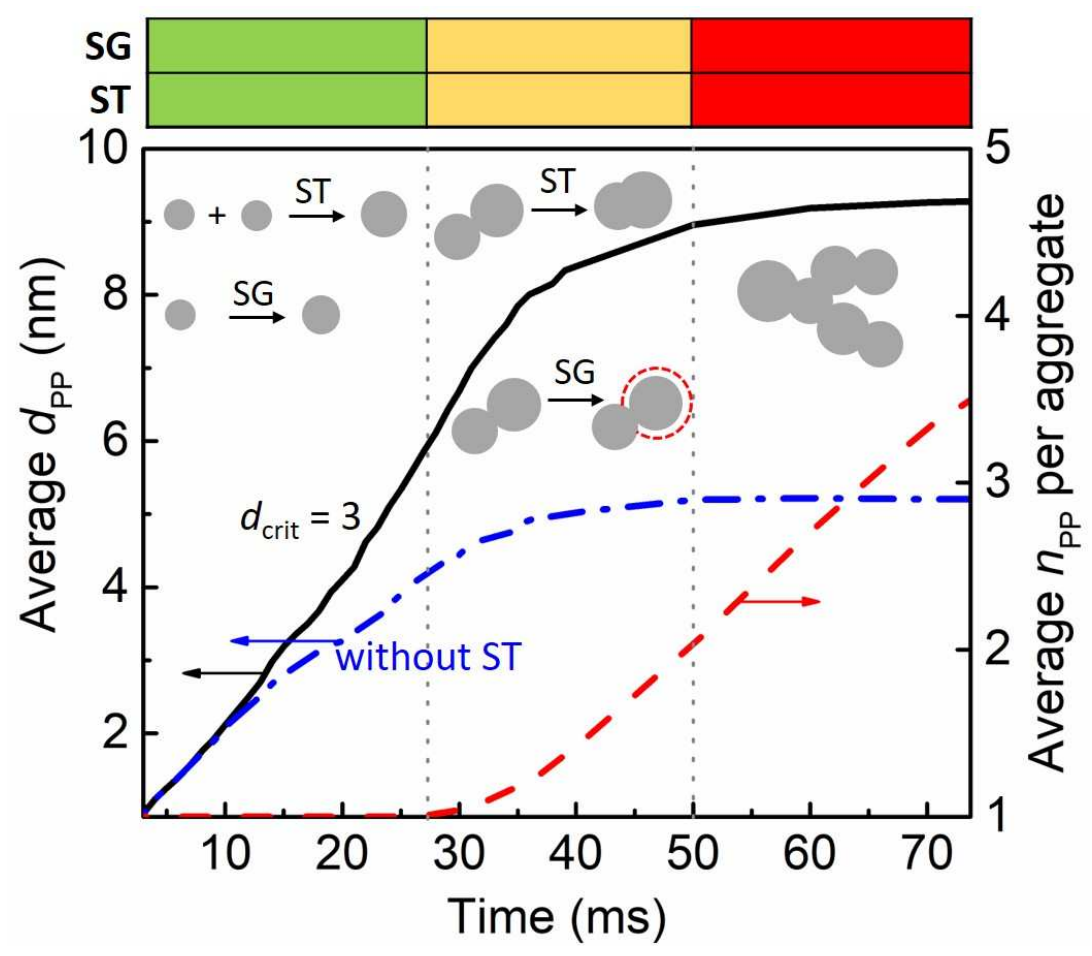

Figure 10: The computed time evolution of average PP diameter (left $\mathrm{Y}$-axis) and average number of PP per aggregate (right Y-axis). The table above suggests the rate of particle processes (SG: surface growth; ST: sintering) by different colors (Green: fast; Yellow: slow; Red: almost stop) at three time periods.

does not affect the size of PPs. Since both surface growth and sintering contribute to the growth of PPs, we investigated the evolution of average $d_{\mathrm{PP}}$ without sintering to give an indication of the respective contribution of these two processes to the growth of PPs. The result is represented by the blue dash-dotted line in Fig. 10. With the sintering sub-model turned off, surface growth becomes the major contributor to the growth of PPs and $d_{\mathrm{PP}}$ ends up at $\sim 5 \mathrm{~nm}$. By contrast, if sintering is incorporated, the average $d_{\mathrm{PP}}$ can reach $\sim 10 \mathrm{~nm}$, much larger than the case with surface growth only and agrees better with the experimental observations.

In addition to the time evolution of average $d_{\mathrm{PP}}$, more detailed information - time evolution of the computed PPSD is illustrated in Fig. 11. The simulated PPSDs and corresponding $\sigma_{\mathrm{g}}$ at five different times: 10, 20, $30,50,73.7 \mathrm{~ms}$ are shown. $73.7 \mathrm{~ms}$ corresponds to the residence time of a 


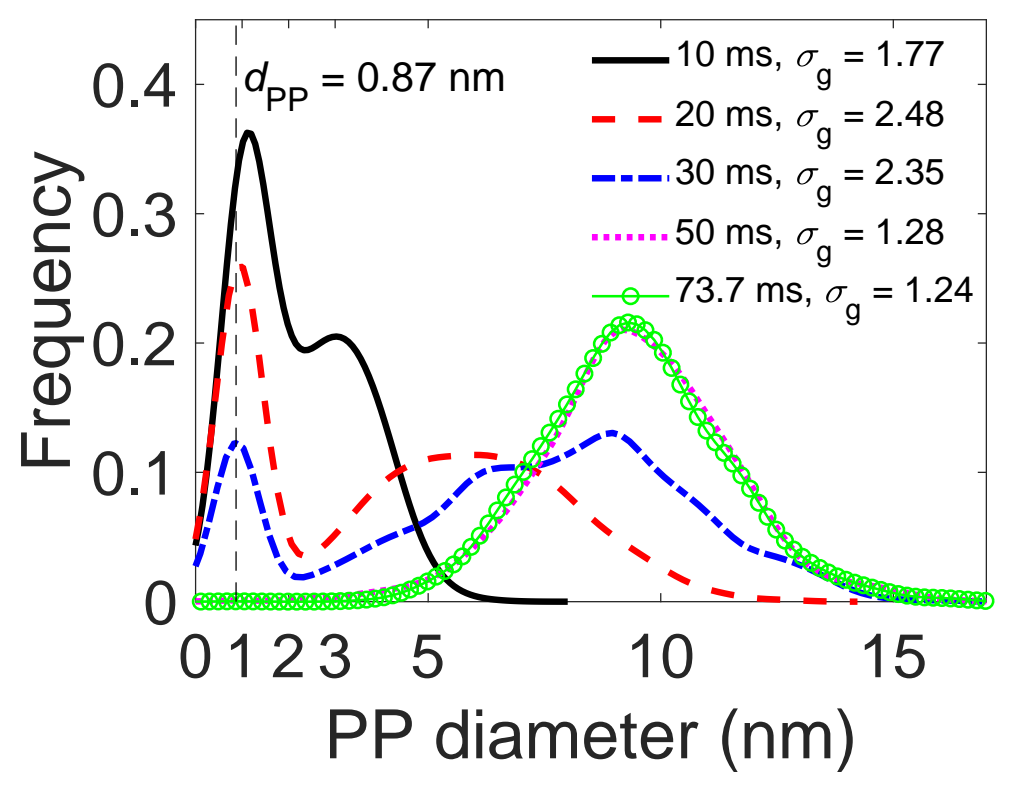

Figure 11: Time evolution of the computed PPSD.

Lagrangian particle travelling from the burner to the stagnation plate at $1.2 \mathrm{~cm}$. The conversion from distance to residence time is performed using the combined axial convective velocity and thermophoretic velocity, as described in our previous work [45, 66]. As shown by Fig. 11, the computed PPSDs evolve from a bimodal distribution (PPSDs at 10, 20 and $30 \mathrm{~ms}$ ) to a unimodal distribution (PPSDs at 50 and $73.7 \mathrm{~ms}$ ). We attribute the first peak of the bimodal PPSDs at earlier time stages to A4 molecules entering the simulation ensemble, because the $d_{\mathrm{PP}}$ corresponding to the first peak is always around $0.87 \mathrm{~nm}$, which is the diameter of A4 molecules in the model. The peak with $d_{\mathrm{PP}}$ slightly larger than $0.87 \mathrm{~nm}$ is caused by the growth of A4 to larger PAHs. By contrast, the second peak of the simulated PPSD can be attributed to the collision related processes, including the collisions between PAHs, PAH and particles or particles, all of which will lead to larger PPs. From $10 \mathrm{~ms}$ to $30 \mathrm{~ms}$, the second peak of the simulated PPSDs moves towards a larger diameter due to simultaneous surface growth and sintering. Meanwhile, the intensity of the first peak keeps decreasing due to the decrease in $\dot{\omega}_{A 4}$, as suggested by Fig. 9. The polydispersity of PPs keeps increasing during $10-30 \mathrm{~ms}$ as suggested by the increasing $\sigma_{\mathrm{g}}$. At $50 \mathrm{~ms}$, the first peak 
of the simulated PPSD corresponding to $\dot{\omega}_{A 4}$ disappears, leaving a unimodal PPSD. After $50 \mathrm{~ms}$, the modelled PPSD remains practically unaltered, as the computed PPSD at $73.7 \mathrm{~ms}$ almost coincides with that at $50 \mathrm{~ms}$. This is understandable because the size of PPs changes either by surface growth or sintering, however, both processes nearly stop after $50 \mathrm{~ms}$, leading to the simulated PPSDs remaining unchanged. Besides, $\sigma_{\mathrm{g}}$ converges to $\sim 1.2$, which is consistent with the experimental measurements for soot particles in premixed flames 69].

\section{Conclusions}

In this work, we simulated soot formation in a premixed ethylene stagnation flame with a DPBM capable of tracking aggregate morphology as well as the chemical composition of soot particles. A thorough parametric sensitivity study was carried out to understand the influence of key particle processes on the computed PPSDs. The computed PPSDs were found to be sensitive to the rate of production of A4, coagulation rate and surface growth rate, which are in accordance with previous work. Besides, we found that instantaneous sintering between small PPs $\left(<d_{\text {crit }}\right)$ played an important role in the computed aggregate morphology while sintering between larger PPs within soot aggregates only had mild influence on the predicted aggregate morphology.

Besides reasonable agreement between the computed and measured PSD of soot particles, good agreement between the computed and measured PPSD and $D_{\mathrm{f}}$ was obtained for an ethylene premixed flame with $H_{\mathrm{p}}=1.2 \mathrm{~cm}$, which supported the current mechanisms contributing to the evolution of soot PPs, i.e. nucleation, coagulation, surface growth and sintering.

Time scale analysis of individual particle processes was performed to determine the dominant processes at different time stages. Combining the results of time scale analysis for individual sooting processes and the time evolution of the average PP size and the number of PP per aggregate, the growth of PP can be divided into three different stages: the first of which has fast surface growth and instantaneous sintering; the second of which has slow surface growth and sintering; while surface growth and sintering almost stop in the third stage. The investigation of time evolution of the computed PPSD demonstrated that the PPSD evolved from bi-modal to unimodal, which can be well explained by the interplay between nucleation, coagulation surface growth and sintering. In addition, the computed PPSDs of soot particles 
in the premixed ethylene flame were shown to be insensitive to the size of aggregate particles.

However, despite of the encouraging agreement achieved between the computed and observed PPSD, more fundamental work regarding key individual particle processes is imperative. For instance, in this work $d_{\text {crit }}=3 \mathrm{~nm}$ was fitted and more fundamental study (like molecular dynamics study) is needed to understand whether the value is appropriate. It is worth emphasizing that the current DPBM provides us with a powerful tool to investigate the key sooting processes by facilitating more comparison between computational results and experimental measurements. Further progress on soot modelling study can be made by reducing the uncertainties of key model parameters.

\section{Acknowledgements}

This project is supported by the National Science Foundation of China (51761125012), and the National Research Foundation (NRF), Prime Minister's Office, Singapore under its Campus for Research Excellence and Technological Enterprise (CREATE) programme. The China Scholarship Council (CSC) is gratefully acknowledged. MK also acknowledges the support of the Alexander von Humboldt Foundation.

\section{References}

[1] H. Wang, Formation of nascent soot and other condensed-phase materials in flames, Proceedings of the Combustion Institute 33 (2011) 41 67. doi:10.1016/j.proci.2010.09.009.

[2] H. Richter, J. Howard, Formation of polycyclic aromatic hydrocarbons and their growth to soot - A review of chemical reaction pathways, Progress in Energy and Combustion Science 26 (2000) 565 - 608. doi:10. 1016/S0360-1285(00)00009-5.

[3] J.-B. Donnet, Carbon black: science and technology, CRC Press, 1993.

[4] A. D'Anna, Combustion-formed nanoparticles, Proceedings of the Combustion Institute 32 (2009) 593 - 613. doi:10.1016/j.proci.2008.09. 005. 
[5] M. Choi, G. Mulholland, A. Hamins, T. Kashiwagi, Comparisons of the soot volume fraction using gravimetric and light extinction techniques, Combustion and Flame 102 (1995) 161 - 169. doi:10.1016/ 0010-2180(94)00282-W.

[6] F. Xu, P. Sunderland, G. Faeth, Soot formation in laminar premixed ethylene/air flames at atmospheric pressure, Combustion and Flame 108 (1997) 471 - 493. doi:10.1016/S0010-2180(96)00200-3.

[7] C. R. Shaddix, K. C. Smyth, Laser-induced incandescence measurements of soot production in steady and flickering methane, propane, and ethylene diffusion flames, Combustion and Flame 107 (1996) 418 452. doi:10.1016/S0010-2180(96)00107-1.

[8] J. Mei, M. Wang, D. Hou, Q. Tang, X. You, Comparative study on nascent soot formation characteristics in laminar premixed acetylene, ethylene, and ethane flames, Energy \& Fuels 32 (2018) 11683-11693. doi:10.1021/acs.energyfuels.8b02852.

[9] Q. Tang, R. Cai, X. You, J. Jiang, Nascent soot particle size distributions down to $1 \mathrm{~nm}$ from a laminar premixed burner-stabilized stagnation ethylene flame, Proceedings of the Combustion Institute 36 (2017) 993 - 1000. doi:10.1016/j.proci.2016.08.085.

[10] A. D. Abid, J. Camacho, D. A. Sheen, H. Wang, Quantitative measurement of soot particle size distribution in premixed flames - the burnerstabilized stagnation flame approach, Combustion and Flame 156 (2009) 1862 - 1870. doi:10.1016/j.combustflame.2009.05.010.

[11] M. Schenk, S. Lieb, H. Vieker, A. Beyer, A. Gölzhäuser, H. Wang, K. Kohse-Höinghaus, Morphology of nascent soot in ethylene flames, Proceedings of the Combustion Institute 35 (2015) 1879 - 1886. doi:10. 1016/j.proci.2014.05.009.

[12] A. D. Abid, N. Heinz, E. D. Tolmachoff, D. J. Phares, C. S. Campbell, H. Wang, On evolution of particle size distribution functions of incipient soot in premixed ethylene-oxygen-argon flames, Combustion and Flame 154 (2008) 775 - 788. doi:10.1016/j.combustflame.2008.06.009.

[13] M. Schenk, S. Lieb, H. Vieker, A. Beyer, A. Gölzhäuser, H. Wang, K. Kohse-Höinghaus, Imaging nanocarbon materials: Soot particles 
in flames are not structurally homogeneous, ChemPhysChem 14 (2013) 3248-3254. doi:10.1002/cphc.201300581.

[14] P. D. Teini, D. M. Karwat, A. Atreya, Observations of nascent soot: Molecular deposition and particle morphology, Combustion and Flame 158 (2011) 2045 - 2055. doi:10.1016/j.combustflame.2011.03.005.

[15] M. L. Botero, D. Chen, S. González-Calera, D. Jefferson, M. Kraft, HRTEM evaluation of soot particles produced by the non-premixed combustion of liquid fuels, Carbon 96 (2016) 459 - 473. doi:10.1016/j. carbon.2015.09.077.

[16] F. Schulz, M. Commodo, K. Kaiser, G. D. Falco, P. Minutolo, G. Meyer, A. D'Anna, L. Gross, Insights into incipient soot formation by atomic force microscopy, Proceedings of the Combustion Institute 37 (2019) 885 - 892. doi:10.1016/j.proci.2018.06.100.

[17] M. Commodo, K. Kaiser, G. D. Falco, P. Minutolo, F. Schulz, A. D'Anna, L. Gross, On the early stages of soot formation: Molecular structure elucidation by high-resolution atomic force microscopy, Combustion and Flame 205 (2019) 154 - 164. doi:10.1016/j . combustflame. 2019.03.042.

[18] M. Frenklach, H. Wang, Detailed modeling of soot particle nucleation and growth, Symposium (International) on Combustion 23 (1991) 1559 - 1566. doi:10.1016/S0082-0784(06)80426-1.

[19] J. Appel, H. Bockhorn, M. Frenklach, Kinetic modeling of soot formation with detailed chemistry and physics: laminar premixed flames of C2 hydrocarbons, Combustion and Flame 121 (2000) $122-136$. doi:10.1016/S0010-2180(99)00135-2.

[20] M. Balthasar, M. Kraft, A stochastic approach to calculate the particle size distribution function of soot particles in laminar premixed flames, Combustion and Flame 133 (2003) 289 - 298. doi:10.1016/ S0010-2180(03)00003-8.

[21] C. Saggese, S. Ferrario, J. Camacho, A. Cuoci, A. Frassoldati, E. Ranzi, H. Wang, T. Faravelli, Kinetic modeling of particle size distribution of 
soot in a premixed burner-stabilized stagnation ethylene flame, Combustion and Flame 162 (2015) 3356 - 3369. doi:10.1016/j . combustflame. 2015.06 .002 .

[22] R. Lindstedt, B. Waldheim, Modeling of soot particle size distributions in premixed stagnation flow flames, Proceedings of the Combustion Institute 34 (2013) 1861 - 1868. doi:10.1016/j.proci.2012.05.047.

[23] M. L. Botero, N. Eaves, J. A. Dreyer, Y. Sheng, J. Akroyd, W. Yang, M. Kraft, Experimental and numerical study of the evolution of soot primary particles in a diffusion flame, Proceedings of the Combustion Institute (2018). doi:10.1016/j.proci.2018.06.185.

[24] M. Kraft, Modelling of particulate processes, KONA Powder and Particle Journal 23 (2005) 18-35. doi:10.14356/kona.2005007.

[25] K. Ono, K. Dewa, Y. Matsukawa, Y. Saito, Y. Matsushita, H. Aoki, K. Era, T. Aoki, T. Yamaguchi, Experimental evidence for the sintering of primary soot particles, Journal of Aerosol Science 105 (2017) 1 - 9 . doi:10.1016/j.jaerosci.2016.11.013.

[26] G. A. Kelesidis, E. Goudeli, S. E. Pratsinis, Flame synthesis of functional nanostructured materials and devices: Surface growth and aggregation, Proceedings of the Combustion Institute 36 (2017) 29 - 50. doi:10.1016/ j.proci.2016.08.078.

[27] P. Mitchell, M. Frenklach, Monte Carlo simulation of soot aggregation with simultaneous surface growth - why primary particles appear spherical, Symposium (International) on Combustion 27 (1998) 1507 1514. doi:10.1016/S0082-0784(98)80558-4.

[28] P. Mitchell, M. Frenklach, Particle aggregation with simultaneous surface growth, Phys. Rev. E 67 (2003) 061407. doi:10.1103/PhysRevE. 67.061407 .

[29] G. A. Kelesidis, E. Goudeli, S. E. Pratsinis, Morphology and mobility diameter of carbonaceous aerosols during agglomeration and surface growth, Carbon 121 (2017) 527 - 535. doi:10.1016/j.carbon.2017. 06.004 . 
[30] M. Balthasar, M. Frenklach, Detailed kinetic modeling of soot aggregate formation in laminar premixed flames, Combustion and Flame 140 (2005) 130 - 145. doi 10.1016/j. combustf lame.2004.11.004.

[31] N. Morgan, M. Kraft, M. Balthasar, D. Wong, M. Frenklach, P. Mitchell, Numerical simulations of soot aggregation in premixed laminar flames, Proceedings of the Combustion Institute 31 (2007) 693 - 700. doi:10. 1016/j.proci.2006.08.021.

[32] R. I. Patterson, M. Kraft, Models for the aggregate structure of soot particles, Combustion and Flame 151 (2007) 160 - 172. doi:10.1016/ j.combustflame.2007.04.012.

[33] R. I. Patterson, J. Singh, M. Balthasar, M. Kraft, W. Wagner, Extending stochastic soot simulation to higher pressures, Combustion and Flame 145 (2006) 638-642. doi:10.1016/j.combustflame.2006. 02.005 .

[34] G. A. Kelesidis, S. E. Pratsinis, Soot light absorption and refractive index during agglomeration and surface growth, Proceedings of the Combustion Institute 37 (2019) 1177-1184. doi:10.1016/j.proci.2018.08. 025 .

[35] G. A. Kelesidis, S. E. Pratsinis, Estimating the internal and surface oxidation of soot agglomerates, Combustion and Flame 209 (2019) 493499. doi:10.1016/j. combustf lame.2019.08.001.

[36] A. Veshkini, S. B. Dworkin, M. J. Thomson, Understanding soot particle size evolution in laminar ethylene/air diffusion flames using novel soot coalescence models, Combustion Theory and Modelling 20 (2016) 707734 .

[37] B. S. Haynes, H. G. Wagner, Soot formation, Progress in energy and combustion science 7 (1981) 229-273.

[38] B. Zhao, K. Uchikawa, H. Wang, A comparative study of nanoparticles in premixed flames by scanning mobility particle sizer, small angle neutron scattering, and transmission electron microscopy, Proceedings of the Combustion Institute 31 (2007) 851-860. 
[39] A. Abid, E. Tolmachoff, D. Phares, H. Wang, Y. Liu, A. Laskin, Size distribution and morphology of nascent soot in premixed ethylene flames with and without benzene doping, Proceedings of the Combustion Institute 32 (2009) 681-688.

[40] J. P. Cain, J. Camacho, D. J. Phares, H. Wang, A. Laskin, Evidence of aliphatics in nascent soot particles in premixed ethylene flames, Proceedings of the Combustion Institute 33 (2011) 533-540.

[41] M. Sander, R. I. Patterson, A. Braumann, A. Raj, M. Kraft, Developing the PAH-PP soot particle model using process informatics and uncertainty propagation, Proceedings of the Combustion Institute 33 (2011) 675 - 683. doi:10.1016/j.proci.2010.06.156.

[42] D. Chen, Z. Zainuddin, E. K. Y. Yapp, J. Akroyd, S. Mosbach, M. Kraft, A fully coupled simulation of PAH and soot growth with a population balance model, Proceedings of the Combustion Institute 34 (2013) 1827 - 1835. doi:10.1016/j.proci.2012.06.089

[43] E. K. Y. Yapp, D. Chen, J. Akroyd, S. Mosbach, M. Kraft, J. Camacho, H. Wang, Numerical simulation and parametric sensitivity study of particle size distributions in a burner-stabilised stagnation flame, Combustion and Flame 162 (2015) 2569 - 2581. doi:10.1016/j.combustflame. 2015.03.006.

[44] C. S. Lindberg, M. Y. Manuputty, E. K. Yapp, J. Akroyd, R. Xu, M. Kraft, A detailed particle model for polydisperse aggregate particles, Journal of Computational Physics (2019). doi:10.1016/j.jcp. 2019.06 .074

[45] D. Hou, C. S. Lindberg, M. Y. Manuputty, X. You, M. Kraft, Modelling soot formation in a benchmark ethylene stagnation flame with a new detailed population balance model, Combustion and Flame 203 (2019) 56 - 71. doi:10.1016/j. combustflame.2019.01.035.

[46] J. Camacho, C. Liu, C. Gu, H. Lin, Z. Huang, Q. Tang, X. You, C. Saggese, Y. Li, H. Jung, L. Deng, I. Wlokas, H. Wang, Mobility size and mass of nascent soot particles in a benchmark premixed ethylene flame, Combustion and Flame 162 (2015) 3810 - 3822. doi:10.1016/j. combustflame.2015.07.018. 
[47] M. Wang, Q. Tang, J. Mei, X. You, On the effective density of soot particles in premixed ethylene flames, Combustion and Flame 198 (2018) 428 - 435. doi $10.1016 / j$. combustflame.2018.10.004.

[48] M. Y. Manuputty, J. Akroyd, S. Mosbach, M. Kraft, Modelling $\mathrm{TiO}_{2}$ formation in a stagnation flame using method of moments with interpolative closure, Combustion and Flame 178 (2017) 135 - 147. doi:10.1016/j. combustflame.2017.01.005.

[49] J. Singh, Detailed soot modelling in laminar premixed flames, Ph.D. thesis, University of Cambridge, 2006.

[50] S. Shekar, W. J. Menz, A. J. Smith, M. Kraft, W. Wagner, On a multivariate population balance model to describe the structure and composition of silica nanoparticles, Computers and Chemical Engineering 43 (2012) 130 - 147. doi:10.1016/j.compchemeng. 2012.04.010.

[51] E. K. Y. Yapp, Numerical simulation of soot in laminar flames, Ph.D. thesis, University of Cambridge, 2016.

[52] A. Raj, M. Celnik, R. Shirley, M. Sander, R. Patterson, R. West, M. Kraft, A statistical approach to develop a detailed soot growth model using PAH characteristics, Combustion and Flame 156 (2009) 896 - 913. doi $10.1016 /$ j. combustflame.2009.01.005.

[53] M. Sander, Mathematical modelling of nanoparticles from gas-phase, Ph.D. thesis, University of Cambridge, 2011.

[54] M. L. Eggersdorfer, D. Kadau, H. J. Herrmann, S. E. Pratsinis, Multiparticle sintering dynamics: From fractal-like aggregates to compact structures, Langmuir 27 (2011) 6358-6367. doi:10.1021/la200546g.

[55] M. L. Eggersdorfer, D. Kadau, H. J. Herrmann, S. E. Pratsinis, Aggregate morphology evolution by sintering: Number and diameter of primary particles, Journal of Aerosol Science 46 (2012) 7 - 19. doi:10.1016/j.jaerosci.2011.11.005.

[56] F. E. Kruis, K. A. Kusters, S. E. Pratsinis, B. Scarlett, A simple model for the evolution of the characteristics of aggregate particles undergoing coagulation and sintering, Aerosol science and technology 19 (1993) $514-526$. 
[57] D. Hou, D. Zong, C. S. Lindberg, M. Kraft, X. You, On the coagulation efficiency of carbonaceous nanoparticles, Journal of Aerosol Science (2019) 105478. doi:10.1016/j.jaerosci.2019.105478.

[58] R. Jullien, Transparency effects in cluster-cluster aggregation with linear trajectories, Journal of Physics A: Mathematical and General 17 (1984) L771.

[59] G. Leon, N. Eaves, J. Akroyd, S. Mosbach, M. Kraft, A new methodology to calculate process rates in a kinetic Monte Carlo model of PAH growth, Combustion and Flame 209 (2019) 133 - 143. doi:10.1016/j. combustflame.2019.07.032.

[60] S. Tsantilis, H. Briesen, S. E. Pratsinis, Sintering time for silica particle growth, Aerosol Science and Technology 34 (2001) 237-246. doi:10. 1080/02786820119149.

[61] M. Frenklach, Method of moments with interpolative closure, Chemical Engineering Science 57 (2002) 2229 - 2239. doi:10.1016/ S0009-2509(02) 00113-6.

[62] CMCL Innovations, $k$ inetics ${ }^{\circledR}, 2016$.

[63] M. Goodson, M. Kraft, An efficient stochastic algorithm for simulating nano-particle dynamics, Journal of Computational Physics 183 (2002) 210 - 232. doi:10.1006/jcph.2002.7192.

[64] R. Patterson, J. Singh, M. Balthasar, M. Kraft, J. Norris, The linear process deferment algorithm: A new technique for solving population balance equations, SIAM Journal on Scientific Computing 28 (2006) 303-320. doi:10.1137/040618953.

[65] E. K. Y. Yapp, R. I. Patterson, J. Akroyd, S. Mosbach, E. M. Adkins, J. H. Miller, M. Kraft, Numerical simulation and parametric sensitivity study of optical band gap in a laminar co-flow ethylene diffusion flame, Combustion and Flame 167 (2016) 320 - 334. doi:10.1016/j. combustflame.2016.01.033.

[66] C. S. Lindberg, M. Y. Manuputty, J. Akroyd, M. Kraft, A two-step simulation methodology for modelling stagnation flame synthesised aggregate nanoparticles, Combustion and Flame 202 (2019) 143 - 153. doi:10.1016/j. combustflame.2019.01.010. 
[67] T. S. Totton, D. Chakrabarti, A. J. Misquitta, M. Sander, D. J. Wales, M. Kraft, Modelling the internal structure of nascent soot particles, Combustion and Flame 157 (2010) 909 - 914. doi:10.1016/j. combustflame.2009.11.013.

[68] Media Cybernetics, Inc., Image-Pro Plus 7, 2018.

[69] H. Oltmann, J. Reimann, S. Will, Single-shot measurement of soot aggregate sizes by wide-angle light scattering (WALS), Applied Physics B 106 (2012) 171-183. 